\title{
No Association of Angiotensin-Converting Enzyme Inhibitor or Angiotensin 2 Receptor Blocker Intake with Acute Kidney Injury in Patients Undergoing Kidney Biopsy
}

\author{
Alexander Friedl ${ }^{a}$ Slobodan Peric ${ }^{b}$ Salome Masghatic Michael Wolzt ${ }^{d}$ \\ Walter H. Hörl ${ }^{c}$ Afschin Soleiman ${ }^{e}$ Valentin Fuhrmann ${ }^{f}$ Dominik G. Haider ${ }^{a}$ \\ ${ }^{a}$ Department of Internal Medicine, Hartmann Hospital, ${ }^{\mathrm{b}}$ Karl Landsteiner Institute for Metabolic and Nephrologic \\ Research, Hietzing Hospital, and Departments of ${ }^{\mathrm{C}}$ Nephrology and Dialysis, ${ }^{\mathrm{d}} \mathrm{Clinical}$ Pharmacology, ${ }^{\mathrm{e}} \mathrm{Clinical}$ \\ Pathology and ${ }^{\mathrm{f} G a s t r o e n t e r o l o g y, ~ U n i v e r s i t y ~ H o s p i t a l ~ V i e n n a, ~ M e d i c a l ~ U n i v e r s i t y ~ o f ~ V i e n n a, ~ V i e n n a, ~ A u s t r i a ~}$
}

\section{Key Words}

Angiotensin-converting enzyme inhibitors $\cdot$ Angiotensin 2 receptor blockers $\cdot$ Acute kidney injury $\cdot$ Kidney biopsy

\begin{abstract}
Background: Treatment with angiotensin-converting enzyme inhibitors (ACEIs) or angiotensin 2 receptor blockers (ARBs) is associated with an increased risk for acute kidney injury after cardiovascular interventions. However, for patients undergoing kidney biopsy, no data is available. Methods: Four hundred and sixty-six patients undergoing kidney biopsy were retrospectively analyzed of whether or not concomitant intake of ACEls or ARBs impairs kidney function. Results: Three hundred and twenty-three patients received ACEls or ARBs or both before kidney biopsy. ACEI/ARB intake had no effect on kidney function compared to patients without this medication (all $p>0.05$ ). Conclusion: Treatment with ACEls or ARBs is not associated with risk of acute kidney injury in subjects undergoing kidney biopsy.
\end{abstract}

Copyright ๑ 2012 S. Karger AG, Basel

\section{KARGER}

Fax +4161306 1234

E-Mail karger@karger.ch

www.karger.com
(C) 2012 S. Karger AG, Basel

$1420-4096 / 12 / 0356-0558 \$ 38.00 / 0$

Accessible online at:

www.karger.com/kbr

\section{Introduction}

Angiotensin-converting enzyme inhibitors (ACEIs) or angiotensin receptor blockers (ARBs) are used in many therapeutic regimens. Although ACEI treatment improves outcome in patients with heart failure and retards the progression of renal disease, its use has been associated with the development of acute kidney injury (AKI) in settings where maintenance of glomerular filtration requires efferent arteriolar constriction, which is blocked by ACEIs or ARBs $[1,2]$. ACEIs/ARBs have been associated with $\mathrm{AKI}$ in different clinical situations such as diabetes, heart failure or in patients with fluid loss [3-5]. ACEI or ARB discontinuation before surgery or interventions results in a reduction in the incidence of periprocedural AKI [6].

We therefore analyzed whether concomitant ACEI or $\mathrm{ARB}$ treatment is associated with a risk for AKI in patients undergoing kidney biopsy in a retrospective review of laboratory tests. 
Table 1. Serum creatinine concentrations and ACEI/ARB treatment in patients with glomerulonephritis, diabetic nephropathy or secondary focal segmental glomerulosclerosis

\begin{tabular}{|c|c|c|c|}
\hline & \multicolumn{2}{|c|}{ Creatinine, $\mathrm{mg} / \mathrm{dl}$} & \multirow[t]{2}{*}{$\mathrm{p}$} \\
\hline & before biopsy & after biopsy & \\
\hline \multicolumn{4}{|l|}{ Glomerulonephritis } \\
\hline No ACE/ARB $(n=115)$ & $1.8(1.0 ; 4.0)$ & $1.7(1.0 ; 4.0)$ & $>0.05$ \\
\hline $\operatorname{ACE}(n=172)$ & $1.4(1.0 ; 2.6)$ & $1.5(1.0 ; 2.7)$ & $>0.05$ \\
\hline $\mathrm{ARB}(\mathrm{n}=35)$ & $2.0(1.5 ; 3.9)$ & $2.0(1.4 ; 3.5)$ & $>0.05$ \\
\hline $\mathrm{ACE}+\mathrm{ARB}(\mathrm{n}=36)$ & $1.5(1.0 ; 2.4)$ & $1.6(1.0 ; 2.4)$ & $>0.05$ \\
\hline ACE or ARB $(n=243)$ & $1.6(1.1 ; 2.7)$ & $1.6(1.0 ; 2.7)$ & $>0.05$ \\
\hline \multicolumn{4}{|l|}{ Diabetic nephropathy } \\
\hline No ACE/ARB $(\mathrm{n}=17)$ & $4.0(2.7 ; 5.2)$ & $4.6(3.2 ; 5.3)$ & $>0.05$ \\
\hline $\operatorname{ACE}(\mathrm{n}=31)$ & $3.0(1.6 ; 3.5)$ & $3.1(1.7 ; 3.5)$ & $>0.05$ \\
\hline $\mathrm{ARB}(\mathrm{n}=16)$ & $3.3(1.5 ; 4.5)$ & $3.3(1.5 ; 4.8)$ & $>0.05$ \\
\hline $\mathrm{ACE}+\mathrm{ARB}(\mathrm{n}=8)$ & $2.7(2.1 ; 4.0)$ & $2.8(2.0 ; 4.7)$ & $>0.05$ \\
\hline ACE or ARB $(n=55)$ & $3.0(1.7 ; 4.2)$ & $3.1(1.7 ; 4.1)$ & $>0.05$ \\
\hline \multicolumn{4}{|c|}{ Secondary focal segmental glomerulosclerosis } \\
\hline No ACE/ARB $(\mathrm{n}=11)$ & $1.7(1.2 ; 4.5)$ & $1.7(1.3 ; 5.1)$ & $>0.05$ \\
\hline $\operatorname{ACE}(n=28)$ & $1.7(1.2 ; 3.0)$ & $1.7(1.1 ; 3.2)$ & $>0.05$ \\
\hline $\mathrm{ARB}(\mathrm{n}=7)$ & $2.4(1.1 ; 3.1)$ & $2.2(1.0 ; 2.8)$ & $>0.05$ \\
\hline $\mathrm{ACE}+\mathrm{ARB}(\mathrm{n}=2)$ & $2.5(1.3 ; 2.3)$ & $2.3(1.2 ; 2.2)$ & $>0.05$ \\
\hline ACE or ARB $(n=37)$ & $1.8(1.2 ; 3.1)$ & $1.7(1.1 ; 3.2)$ & $>0.05$ \\
\hline
\end{tabular}

Data are medians (IQR). Wilcoxon rank test of creatinine before and after kidney biopsy.

\section{Methods}

Retrospective data from 466 patients who underwent kidney biopsy between 1992 and 2009 were included in the analysis. The study protocol and data handling procedure was approved by the Ethics Committee of the Medical University of Vienna. The histological classification of glomerulonephritis, diabetic nephropathy or secondary focal segmental glomerulosclerosis in the biopsy material was derived from laboratory reports of the Department of Pathology at the Vienna General Hospital. Creatinine measurements as a marker of renal injury were available within 2 weeks before and $24 \mathrm{~h}$ after kidney biopsy. Patients received standard doses of ACEIs and ARBs. Additional nephrotoxic medication was interrupted during the trial.

\section{Statistical Analysis}

For data description, results are presented as medians and 25$75 \%$ interquartile range (IQR) or means and SD, as appropriate. For univariate analysis, the Mann-Whitney U test or the $\chi^{2}$ test were used as appropriate. Potential predictors were defined a priori or based on associations in the univariate analysis at a conservative threshold $(\mathrm{p}<0.10)$. We used SPSS Statistics for data management and calculations. A two-sided p value less than 0.05 was considered statistically significant.

\section{Results}

Patients had a median age of 60 years (IQR $45 ; 70)$ and 183 (39\%) were female. Three hundred and fifty-eight patients were diagnosed with glomerulonephritis, 46 with secondary focal segmental glomerulosclerosis and 72 with diabetic nephropathy. Overall, 222 patients had ACEI monotherapy (48\%), 56 patients had ARB monotherapy (12\%) and 45 patients had a combination of ACEI and ARB treatment (10\%). The median creatinine value was $1.8 \mathrm{mg} / \mathrm{dl}$ (IQR $1.1 ; 3.2)$ before biopsy and $1.8 \mathrm{mg} / \mathrm{dl}$ (IQR $1.1 ; 3.5)$ after biopsy ( $\mathrm{p}>0.05)$.

In patients without ACEI or ARB therapy, creatinine values were $1.65 \mathrm{mg} / \mathrm{dl}$ (IQR 1.0;2.8) before and $1.66 \mathrm{mg} /$ $\mathrm{dl}$ (IQR 1.0; 3.1) after biopsy; in patients with ACEI or ARB therapy, creatinine values were $1.78 \mathrm{mg} / \mathrm{dl}$ (IQR 1.1; 3.0) before and $1.74 \mathrm{mg} / \mathrm{dl}$ (IQR 1.1; 3.3) after biopsy ( $\mathrm{p}>$ $0.05)$. There were no differences between the changes in creatinine before and after biopsy across the treatment groups ( $\mathrm{p}>0.05$; table 1 ).

\section{Discussion}

Our studies demonstrate that ACEI or ARB use in patients undergoing kidney biopsy is not associated with acutely impaired kidney function after the procedure.

Although continued ACEI or ARB therapy is associated with improved survival and retarded progression of renal disease in patients at cardiovascular risk $[6,7]$, concerns about development of AKI in situations associated with decreased glomerular filtration pressure have been raised $[2,6,8]$. ACEI reportedly resulted in $28 \%$ increased risk of AKI following surgery, suggesting that dosing of these substances should be temporarily interrupted prior to cardiovascular interventions [6]. AKI after cardiovascular interventions commonly occurs between 24 and 48 $\mathrm{h}$ [6] and depends on blood pressure and type of blood flow during cardiac surgery (pulsatile vs. continuous flow) [9]. During this time window of peak kidney injury incidence, no change in creatinine was detectable in this retrospective cohort of subjects. Therefore, ACEI or ARB treatment does not appear as a risk factor for transient renal impairment when kidney biopsies are mandated. 


\section{References}

$>1$ Schoolwerth AC, Sica DA, Ballermann BJ, Wilcox CS, Council on the Kidney in Cardiovascular Disease and the Council for High Blood Pressure Research of the American Heart Association: Renal considerations in angiotensin converting enzyme inhibitor therapy: a statement for healthcare professionals from the Council on the Kidney in Cardiovascular Disease and the Council for High Blood Pressure Research of the American Heart Association. Circulation 2001; 104:1985-1991.

$>2$ Toto R: Angiotensin II subtype 1 receptor blockers and renal function. Arch Intern Med 2001;161:1492-1499.
3 Albareda M, Merce MD, Corcoy R: Reversible impairment of renal function associated with enalapril in a diabetic patients. CMAJ 1998;159:1279-1281.

-4 Cruz CS, Cruz LS, Silva GR, Marcillio de Souza CA: Incidence and predictors of development of acute renal failure related to treatment of congestive heart failure with ACE inhibitors. Nephron 2007; 105:C77-C83.

5 Stirling C, Houston J, Robertson S, Boyle J, Allan A, Norris J, Isles C: Diarrhea, vomiting and ACE inhibitors: an important cause of acute renal failure. J Hum Hypertens 2003; 17:419-423.
6 Arora P, Rajagopalam S, Ranjan R, Kolli H, Singh M, Venuto R, Lohr J: Preoperative use of angiotensin-converting enzyme inhibitors/angiotensin receptor blockers is associated with increased risk for acute kidney injury after cardiovascular surgery. Clin J Am Soc Nephrol 2008;3:1266-1273.

7 Fitchett D: Result of the ONARGET and TRANSCEND studies: an update and discussion. Vasc Health Risk Manag 2009;5:2129.

8 Brown NJ, Vaughan DE: Angiotensin-converting enzyme inhibitors. Circulation 1998; 97:1411-1420.

$>9$ Abu-Omar Y, Ratnatunga C: Cardiopulmonary bypass and renal injury. Perfusion 2006;21:209-213. 